\title{
The Optical Works of Sir Howard Grubb, Parsons and Company.
}

A FEW years ago it was very difficult to obtain a A large object glass for an astronomical telescope. The optician would only promise a glass conditionally on his being able to procure suitable discs. For example, the director of the Johannesburg Observatory

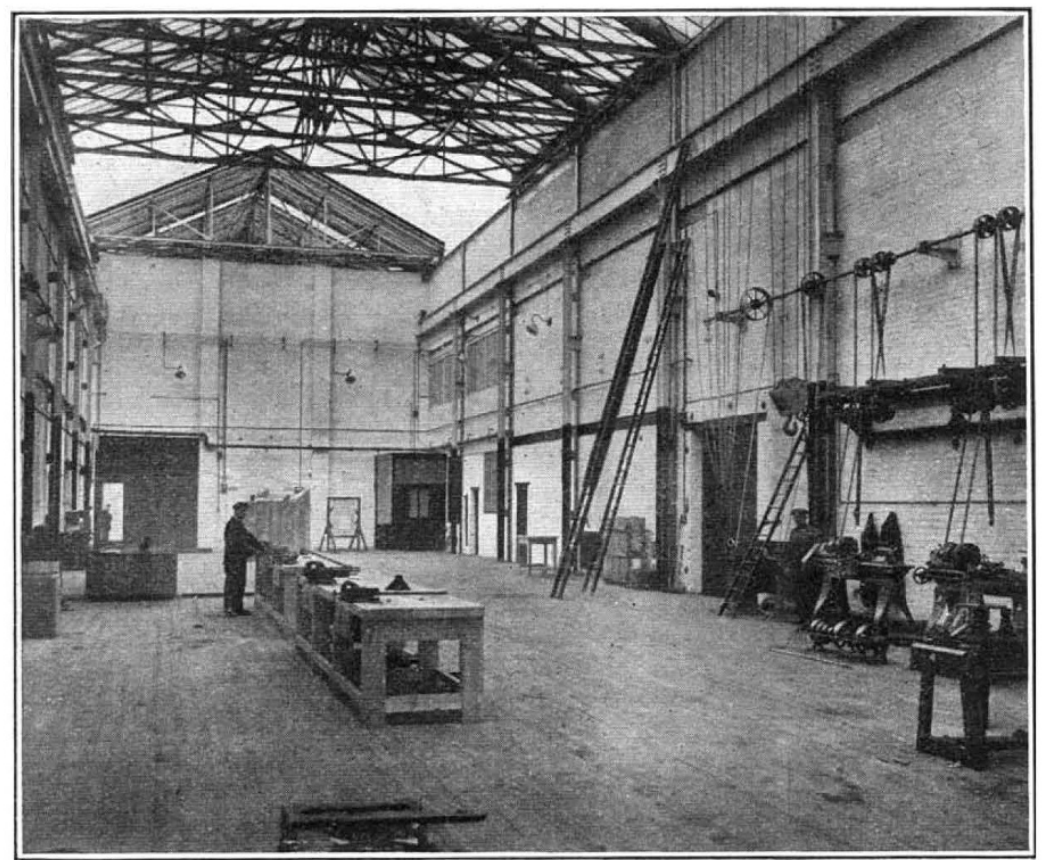

FIG. I.-Erecting bay showing sliding roof partly open.

placed a contract for a 26 -inch refractor in I909, and four years later, in I9r 3 , he reported that "it is hoped that glass discs will be obtained shortly." Large discs of optical glass are required only rarely, and their manufacture is a delicate operation requiring special plant; consequently very few people make them.

British astronomers were greatly pleased when the manufacture of large discs of optical glass was taken up by Sir Charles Parsons, who acquired the business of the Derby Crown Glass Works from Messrs. Wood Brothers, in r92 r. Sir Charles Parsons has an hereditary interest in astronomy and the manufacture of large astronomical telescopes, as his father, the Earl of Rosse, built the famous six-foot reflecting telescope at Birr Castle, Parsonstown, King's County, Ireland. This early interest doubtless influenced him in taking up the manufacture of astronomical instruments from beginning to end-the manufacture of glass, the grinding and figuring of lenses and mirrors and the mechanical parts of telescopes. Near the beginning of 1925 he acquired the old-established business of Sir Howard Grubb. This famous firm was founded by Thomas Grubb a hundred years ago, and developed by the optical and mechanical skill of Sir Howard Grubb, under whose direction many fine telescopes, refractors, and reflectors have been produced. In I9I 8 the works were moved from Dublin to St. Albans in connexion with the manufacture of periscopes for the Navy, instruments which have been a standard product of the firm since the date of the first British submarine.
New works were set up in 1926 at Walker Gate, Newcastle, in close proximity to the well-known works of Messrs. C. A. Parsons and Co., Ltd., makers of steam turbines, electrical machinery, and searchlight mirrors. Close association with large engineering works is a great asset for makers of astronomical instruments. For small telescopes comparatively small plant is required, but for large ones the resources of engineering works with machines of the necessary size and accuracy are essential. In such accessories as large domes and rising floors, which are necessary with big instruments, large machinery is also required. For all heavy machine work the large machine shops of the Heaton works of Messrs. C. A. Parsons and Co. will be used. Nor must the great advantage be overlooked of the interchange of ideas among the staff, made possible by close association with the larger world of engineering.

An internal view of the principal bay of the new optical works is shown in Fig. I. An important feature of this building is the provision for sliding off a large portion of the glass roof by carrying it on a supporting gantry moved by electrically operated motors. The shop possesses a five-ton electric travelling crane ; one end of the bay is fitted up as a machine and fitting shop, and the other is used for the erection of instruments. Means of testing large instruments in course of construction by actual observation of

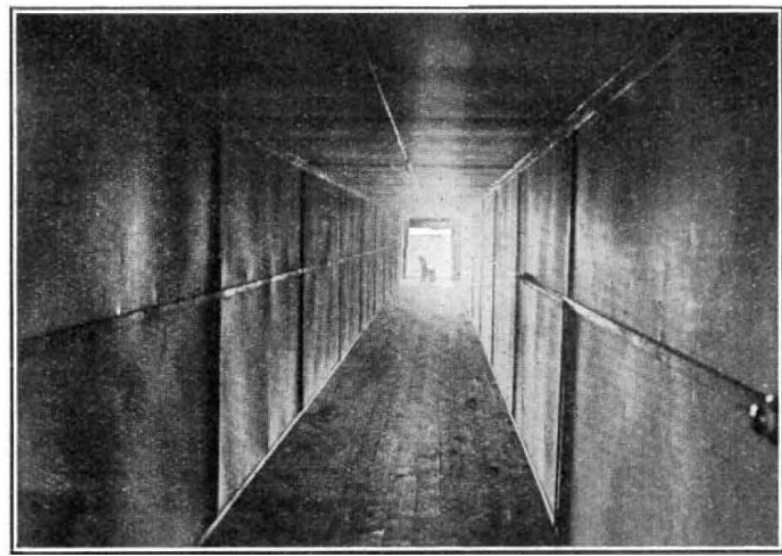

FIG, 2.--Insulated tunnel for the horizontal testing of mirrors and objectives.

stars are thus provided. Generally this is a matter of difficulty at optical works, but however well the laboratory tests may be satisfied, the purchaser of a telescope, as well as the maker, wishes to see how the instrument performs the end for which it is intended, before it is taken away from the works and erected in a possibly distant observatory. 
In the transfer of the optical works from St. Albans is given of the mounting and testing of the mirror. to Newcastle the essential personnel as regards both The departure of the mirror from paraboloidal stace staff and workmen was retained. One establishment is in complete continuity with the other, and it may well be that some of the improvements in the fitting up have been suggested by the previous long experience of the firm of Sir Howard Grubb. The means for testing large mirrors and objectives in the course of construction have been carefully planned. While in position on the polishing machine they can be conveyed by an electrical lift to the bottom of a shaft belonging to the optical testing room. Much labour and time is thus saved in the course of polishing a large mirror or objective which will be tested many times. Fig. 2 shows the horizontal testing tunnel. This is roo feet in length, and gives the means of testing mirrors and objectives in a room of constant temperatures and free from disturbing effects of air currents. The rough polishing shop is shown in Fig. 3 .

Among the instruments already constructed by the firm are a seven-

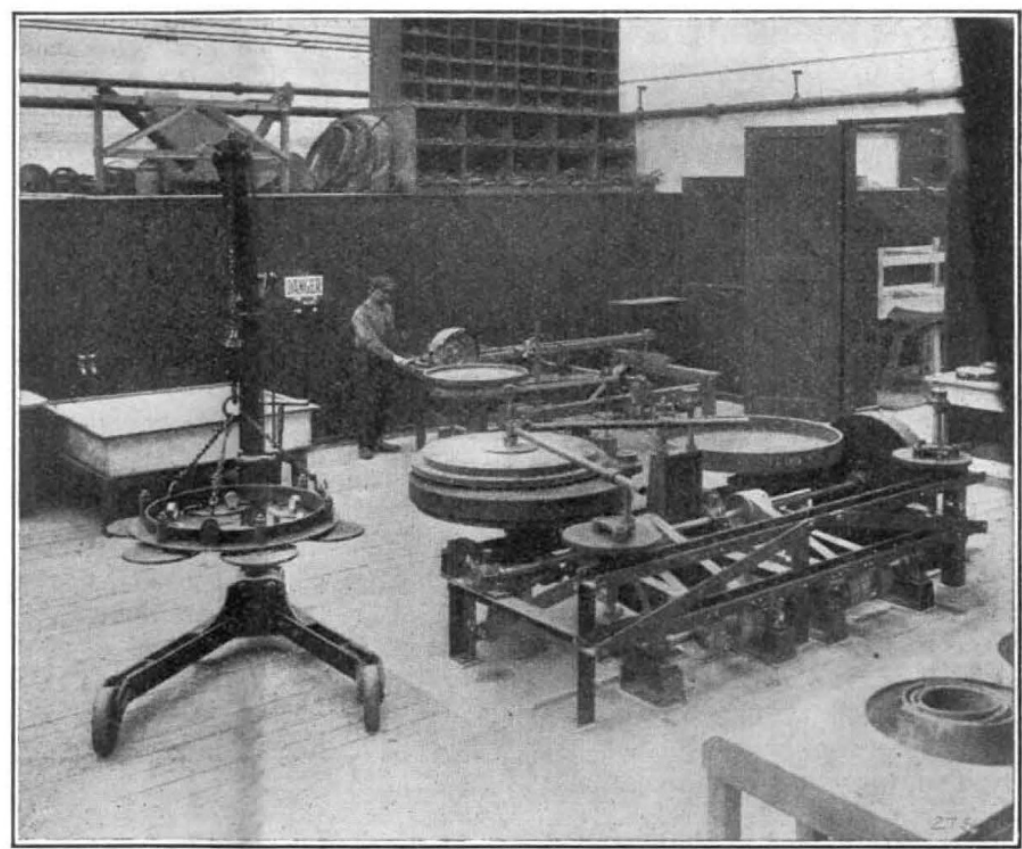

FIG. 3.-Optical roughing shop. metre solar spectrograph for the Pulkovo Observatory $\mid$ is found to be of the order of one-tenth of a waveand a 40-inch reflecting telescope for the Observatory length, showing the mirror to be of very perfect

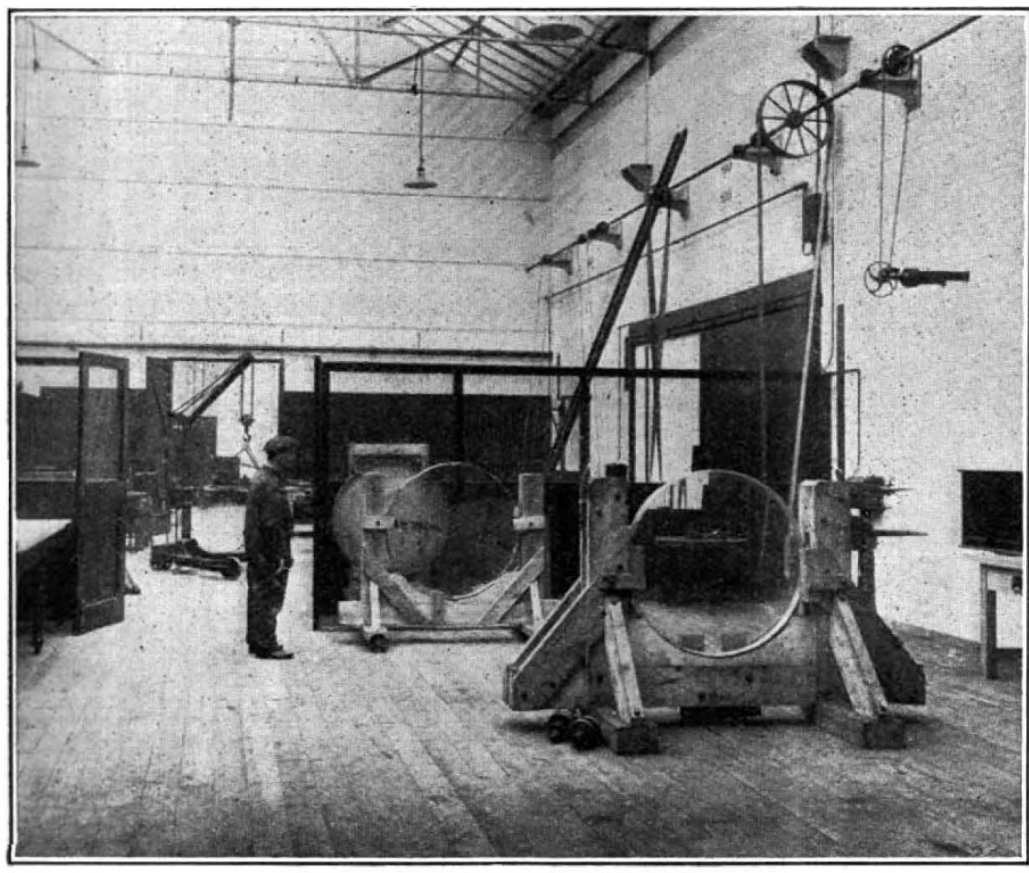

Frg. 4.-Optical discs for $4 \mathrm{I}$-in. objective.

These discs were manufactured by The Parsons Optical Glass Company at Derby. figure. A description of the telescope, and of its mounting and control, was given in Nature of April I 2,1924 .

At the present time, Sir Howard Grubb, Parsons and Co. are engaged on the ambitious task of constructing a refracting telescope with an object glass of $4 \mathrm{I}$ inches diameter. When completed, this telescope, which is also intended for the Simeis Observatory, will have a slightly larger aperture than that of the Yerkes Observatory. The focal length will, however, not be so long, as the instrument is designed for photographic rather than visual work. The discs have already been made at the Crown Derby works, and Fig. 4 shows them in the optical testing shop in Newcastle. Some time ago it was reported by a news agency that the discs had failed to satisfy the optical tests specified, but, as was announced in Nature of June r9, p. 868, the statement was entirely erroneous. The progress of this large of Simeis in Southern Russia. In the annual report telescope will be watched with great interest and of the Observatory, published in the Vierteljahrschrift, and quoted in NATURE of July I7, p. 97, an account in confidence that a very fine instrument will be constructed. 